\title{
Lisuride Reduces Psychomotor Retardation during Withdrawal from Chronic Intravenous Amphetamine Self-Administration in Rats
}

Luigi Pulvirenti, M.D. and George F. Koob, Ph.D.

\begin{abstract}
Withdrawal from chronic use of psychostimulant drugs in humans induces a clinical syndrome characterized by mtigue, psychomotor depression, anhedonia, and disturbances of sleep. Spontaneous locomotor activity and atalepsy were assessed in rats during withdrawal from a shedule of intravenous self-administration of high doses domphetamine. At 2 and 4 days after cessation of mphetamine self-administration, rats showed a state of pychomotor retardation as measured by reduction of bocmotor activity and increased catalepsy. In search of a possible pharmacologic means of intervention for such
\end{abstract}

behavioral changes, the effect of repeated treatment with the nonaddictive ergot derivative lisuride during the withdrawal phase was evaluated. At a dose devoid of any effects on locomotor activity, lisuride completely prevented the reduction in locomotor activity and the increase in catalepsy produced by amphetamine withdrawal. These results suggest the need for further studies on lisuride as a possible novel treatment during withdrawal from psychostimulant drugs in humans. [Neuropsychopharmacology 8:213-218, 1993]
ICY WORDS: Amphetamine; Drug self-administration; Dopamine; Animal models of depression; Lisuride; Bychostimulant withdrawal

The growth of psychostimulant drug addiction in North America has reached epidemic proportions over the past few years. The parallel increase in the number of hospital admissions with such diagnoses has allowed nosological identification and characterization of the withdrawal syndrome that follows abrupt discontinuation of the use of cocaine, amphetamine, or methamphetamine. The syndrome is mainly characterized by btigue, depression of mood, anhedonia, psychomotor retardation, hypersomnia, and hyperphagia together

From the Department of Neuropharmacology, The Scripps Research trstitute, La Jolla, California.

Address reprint requests to: Luigi Pulvirenti, M.D., Biochemical Pychopharmacology Unit, "C. Mondino" Foundation, Department dNeurology, University of Pavia, Via Palestro 3, Pavia 27100, ITALY.

Received August 2, 1991; revised July 9, 1992; accepted July 15, 1992. with intensecraving for the drug: such symptomatology usually encompasses various phases of withdrawal and lasts for a few weeks (Gawin and Kleber, 1986). Episodes of craving for the abused drug are particularly pronounced and are considered to be one of the major motivating factors leading to relapse in the addictive process. It is also believed that withdrawal dysphoria may contribute, as a negative reinforcer, to drugseeking behavior. In accordance with this hypothesis, it is possible that the neural substrates of the limbic forebrain responsible for drug reward may also mediate, to some extent, withdrawal dysphoria (Pulvirenti et al. 1991). Finally, only tricyclic antidepressants have, to date, proven clinically efficacious in reducing withdrawal depression, with bromocriptine, a dopamine (DA) agonist, showing some efficacy in reducing craving for cocaine (Dackis and Gold 1985a; Gawin and Kleber 1984; Tennant and Sagherian 1987).

Lisuride is a nonaddictive ergot derivative known to stimulate postsynaptic DA receptors (Uzumaki et al. 
1982; Horowski and Wachtel 1976; Schechter 1984; Rosenfeld and Makman 1981). In a recent study, it was suggested that lisuride may reduce intravenous cocaine self-administration in rats (Pulvirenti and Koob submitted). This is in accordance with previous findings suggesting a critical role for dopamine in the maintenance of intravenous psychostimulant self-administration in various species (Markou and Koob 1992; Roberts and Vickers 1984; Roberts et al. 1977, 1980). In addition, experimental and clinical studies have suggested that a state of DA depletion may occur during cocaine withdrawal (Wyatt et al. 1988; Gawin and Kleber 1985; Dackis and Gold 1985b). A DA agonist would therefore be expected to exert a normalizing action on the endogenous DA tone temporarily disrupted by repeated exposure to amphetamine.

The aim of the present study was: 1) to quantify the psychomotor retardation that follows withdrawal from chronic intravenous self-administration of high doses of amphetamine, and 2) to study the effect of treatment with lisuride after drug discontinuation on such behavioral abnormalities.

The results presented here show that withdrawal from self-administration of high-dose intravenous amphetamine induced reduction of spontaneous locomotor activity and increased catalepsy, and the development of this syndrome was prevented by repeated treatment with lisuride.

\section{MATERIALS AND METHODS}

Male Wistar rats (Charles River, Kingston, NY), weighing between 200 and $225 \mathrm{~g}$ at the start of the experiment, were housed three to a cage and provided with ad libitum access to food and water and maintained on a 12-hour light/dark cycle (lights on from 4:00 A.M.4:00 P.M.).

All animals for self-administration studies were surgically prepared under halothane anesthesia with a chronic silastic catheter implanted into the external jugular vein. The catheter/polyethylene assembly consisted of silastic tubing attached to a guide cannula that was bent at a right angle. This junction was glued and the guide cannula was embedded into a 1-inch square of marlex mesh that was secured with silex. The catheter was passed subcutaneously from the rat's back to the jugular vein where it was implanted. The polyethylene assembly was then mounted on the animal's back. A stylet was inserted into the guide cannula protruding from the animal's back to maintain a closed system and, therefore, prevent clogging of the cannula.

For self-administration testing, a cannula-connector assembly that was connected to a swivel and syringe pump as described by Roberts et al. $(1977,1980)$ was attached to the polyethylene assembly mounted on the animal's back immediately prior to the start of each session. The cannula connector was removed following the completion of a self-administration session and replaced with the guide cannula stylet.

Four days following surgery, 14 rats were allowed 15-hour access every day (5:00 P.M. to 8:00 A.M.) for 10 days to a metal lever mounted on the side wall of a standard operant-conditioning cage. The cages themselves were housed inside sound-attenuating chambers. Alever press resulted in an intravenous injection of $0.1 \mathrm{ml}$ of d-amphetamine sulphate $(0.12 \mathrm{mg} / \mathrm{kg}$ per injection, or $0.325 \mu \mathrm{mol} / \mathrm{kg}$ per injection) dissolved in $0.9 \%$ physiologic saline and delivered over a period of 4 seconds. A swivel system allowed free movement of the animal in the cage. Coincident with the onset of the injection, a stimulus light was illuminated for 20 seconds during which time the lever pressing did not result in reinforcement. Lever presses during the period when the signal light was not lit were reinforced on a continuous reinforcement schedule. Control rats $(n=11)$ were injected with an equal volume of passive intravenous physiologic saline infusion by an experimenter.

Following completion of the 10-day self-administration period, spontaneous locomotor activity was tested on days 1,2 , and 4 during withdrawal. Since locomotor testing was performed during the dark phase (5:00 P.M. to 8:00 A.M.) and the last self-administration session ended at 8.00 A.M., day 1 of withdrawal actually corresponded to 33 hours after the end of intravenous self-administration. Photobeam interruption was recorded for 180 minutes in photocell cages as described previously (Joyce and Koob 1981).

A separate group of 24 rats was used in the second part of the study. Sixteen rats were trained to selfadminister amphetamine as described above; eight rats received experimentally administered saline as described above. At the end of the 10-day self-administration period, the amphetamine rats were treated with either lisuride $(n=8)(0.2 \mathrm{mg} / \mathrm{kg} \mathrm{IP}$, or $0.44 \mu \mathrm{mol} / \mathrm{kg})$ or saline $(n=8)(1 \mathrm{ml} / \mathrm{kg} \mathrm{IP})$ twice daily at $(8: 00 \mathrm{~A} . \mathrm{M}$. and 8:00 P.M. for 4 days).

For the study designed to test the effect of such repeated treatment with lisuride on spontaneous locomotor activity in naive rats, four animals were injected with one of four different doses of lisuride $(0,0.05,0.1$, and $0.2 \mathrm{mg} / \mathrm{kg} \mathrm{IP}$, or $0,0.11,0.22$, and $0.44 \mu \mathrm{mol} / \mathrm{kg}$, respectively, $n=16$ rats) twice daily at 8:00 A.M. and 8:00 P.M. for 4 days. Animals were then tested as described above. The injection schedule was chosen to avoid the peak effect of lisuride action during locomotor testing.

Catalepsy testing was performed in the same rats during day 4 of withdrawal, at the end of the locomotor testing. Both forepaws of each rat were placed on 


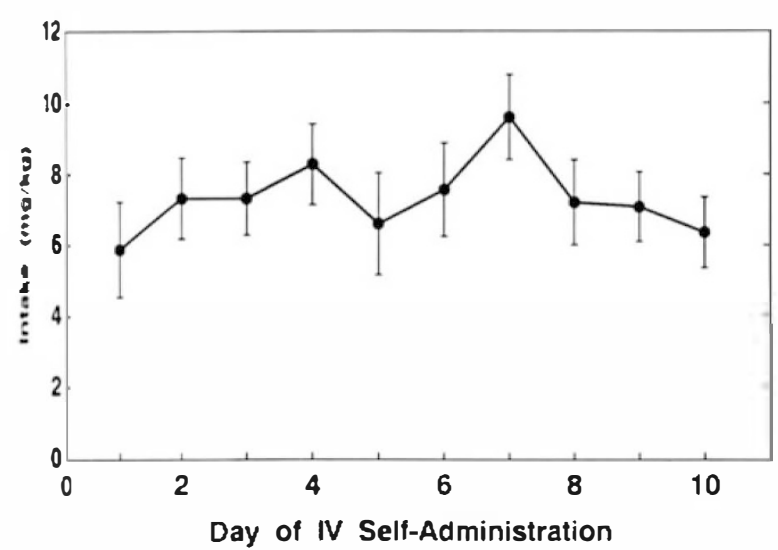

Figure 1. Amphetamine intake during daily 15-hour IV selfthinistration sessions. Values represent mean \pm SEM for 8 rats. The average intake was $7.37 \mathrm{mg} / \mathrm{kg}$.

Ibar $9 \mathrm{~cm}$ from the floor. The time elapsed until each nt repositioned both forepaws on the floor was reorded by an experimenter blind to the treatment.

Results were compared using a two-way analysis dvariance with repeated measures, followed by posthoc Newman-Keul's test or a Student's $t$-test, where spropriate.

The d-amphetamine sulphate was obtained from SGMA (St. Louis, MO), lisuride hydrogen maleate was agenerous gift of Schering AG, (Berlin, Germany). All drugs were dissolved in physiologic saline solution.

\section{RESULTS}

that were allowed 15-hour daily access to intravenous mphetamine self-administration showed a drug intake mnging between 5.9 and $9.6 \mathrm{mg} / \mathrm{kg}$, with an average d $7.37 \mathrm{mg} / \mathrm{kg}$ (Fig. 1). Following cessation of this schedve of drug self-administration, spontaneous locomotor

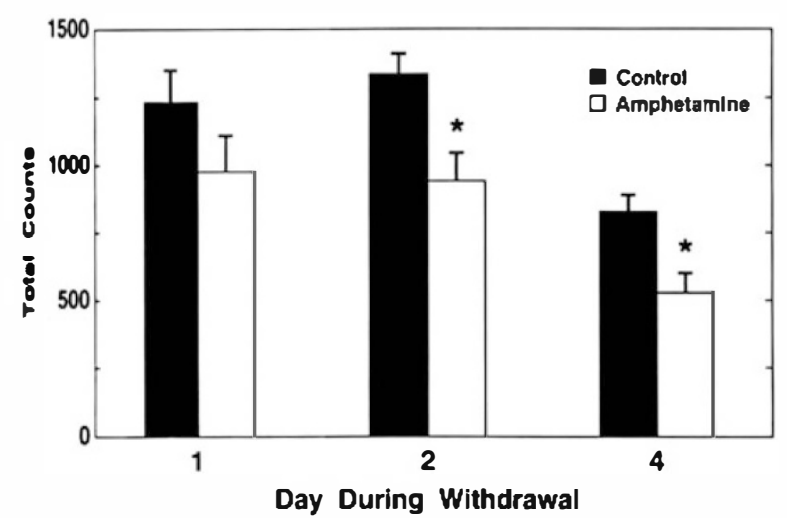

Fure 2. Locomotor activity during withdrawal from chronic mphetamine self-administration. Values represent mean \pm SEM (control: $n=11$; amphetamine: $n=14$ ) of total phobeam interruption during 180 minutes. " $p<0.05$.

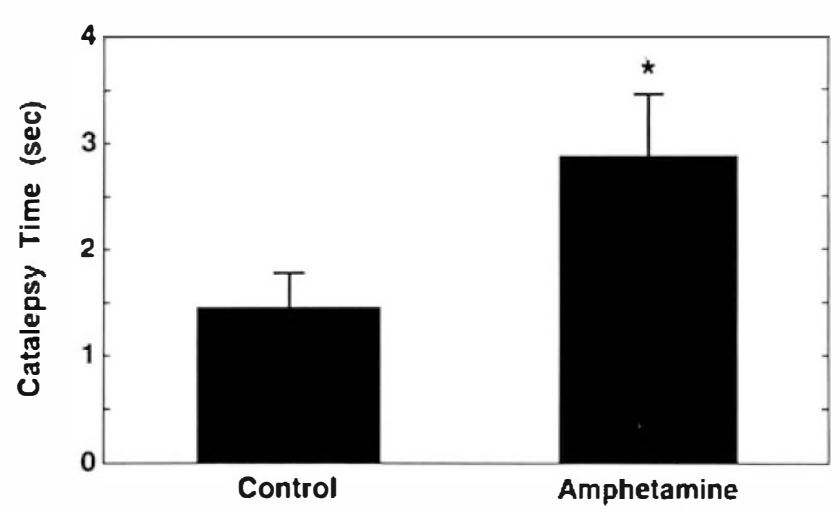

Figure 3. Catalepsy time during withdrawal from chronic amphetamine self-administration in the same animals represented in Figure 2. The forepaws of each rat were placed on a bar $9 \mathrm{~cm}$ from the floor. Values represent mean $\pm S E M$ of time elapsed until each rat (control: $n=11$; amphetamine: $n=14$ ) repositioned both forepaws on the floor. " $p<0.05$.

activity was significantly lower in rats withdrawing from amphetamine self-administration, compared to control animals (Fig. 2). Analysis of variance revealed that there was a main effect of treatment $(F=9.49, d f=1,23, p<$ $0.01)$, a main effect of time $(F=14.49, d f=2,23, p<$ $0.01)$, and no significant treatment $\times$ time interaction $(F<1, d f=2,46, N S)$. Comparison at the various levels revealed that statistical significance was reached at day $2(F=9.41, d f=1,23, p<0.01)$ and day $4(F=5.79$, $d f=1,23, p<0.05)$. Similarly, amphetamine-treated rats showed increased catalepsy compared to control animals. (Fig. 3), as measured by the bar test $(t=-2.21$, $d f=23, p<0.05)$.

The second part of the study was designed to assess the effect of lisuride administered during the withdrawal phase on the behavioral changes observed during the first part of the study. The control experiment illustrated in Figure 4 shows that chronic (4-day) treat-

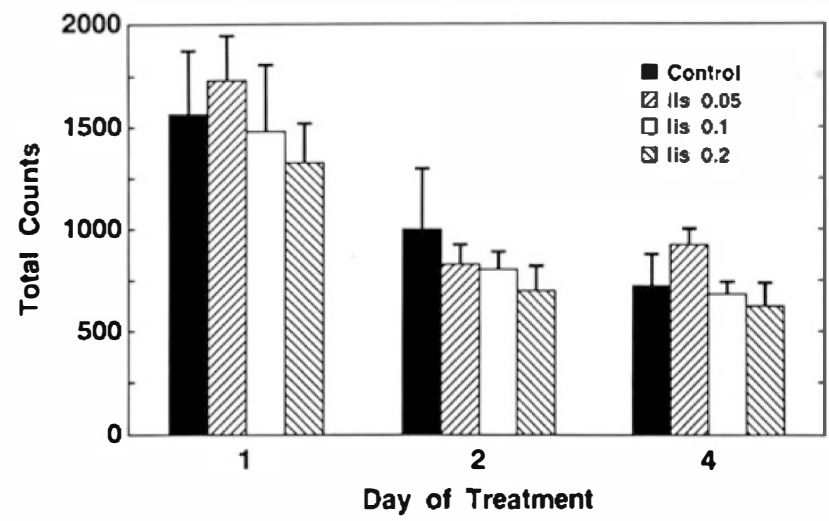

Figure 4. Effect of repeated treatment with lisuride (expressed in $\mathrm{mg} / \mathrm{kg}$, IP twice daily) on locomotor activity in naive rats. Values represent mean $\pm \operatorname{SEM}(n=4$ per group). For details on treatment schedule, see text. 


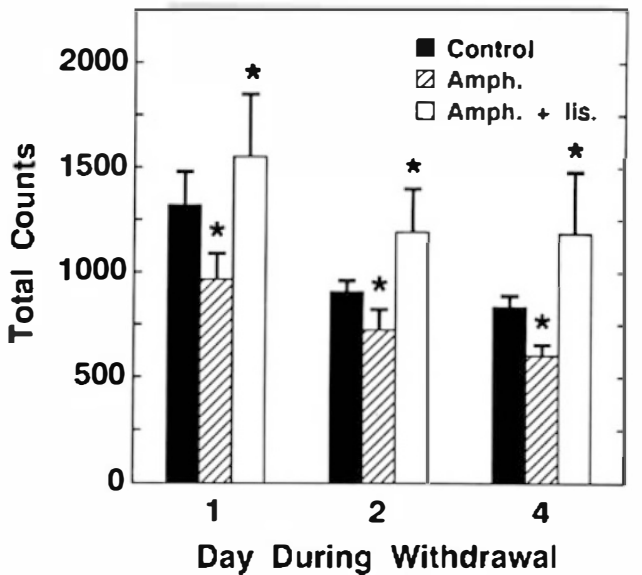

Figure 5. Effect of repeated treatment with lisuride $(0.2$ $\mathrm{mg} / \mathrm{kg}$ IP twice daily for 4 days) on locomotor activity during withdrawal from chronic amphetamine self-administration. Values represent mean \pm SEM ( $n=8$ per group) of total photobeam interruption during 180 minutes. ${ }^{*} p<0.05$ vs. control.

ment with lisuride per se, at the schedule employed, did not affect spontaneous locomotor activity. There was no main effect of drug $(F<1, d f=3,12, N S)$, a main effect of time $(F=25.75, d f=2,12, p<0.01)$, and no significant drug $\times$ time interaction $(F<1, d f=6,24$, NS). In contrast, repeated treatment with lisuride $(0.2$ $\mathrm{mg} / \mathrm{kg}$ IP) during withdrawal (Fig. 5) completely reversed the reduction of locomotor activity induced by cessation of amphetamine availability $(F=10.47$, $d f=2,91, p<0.001)$. Comparison at the various levels revealed that statistical significance was reached at day $1(F=3.447, d f=2,28, p<0.05)$, day $2(F=4.525, d f=$ $2,28, p<0.05)$, and day $4(F=3.87, d f=2,28, p<0.05)$. This was accompanied by reversal of the postamphetamine increased catalepsy in the same rats $(F=4.01$, $d f=2,21, p<0.05$ ) (Fig. 6).

\section{DISCUSSION}

Withdrawal from a chronic schedule of intravenous selfadministration of high dose amphetamine induced a state of psychomotor retardation as measured by reduction of spontaneous locomotor activity and increased catalepsy. Treatment with lisuride after amphetamine suspension completely prevented the development of such behavioral changes.

Abrupt cessation of chronic administration of psychostimulant drugs in man is followed by a clinical syndrome that includes depression of mood, anhedonia, and disturbances of sleep (Gawin and Kleber 1986). Unlike other forms of depression, the occurrence of these symptoms is fairly predictable and limited in time but, similarly to endogenous depression, can be reversed

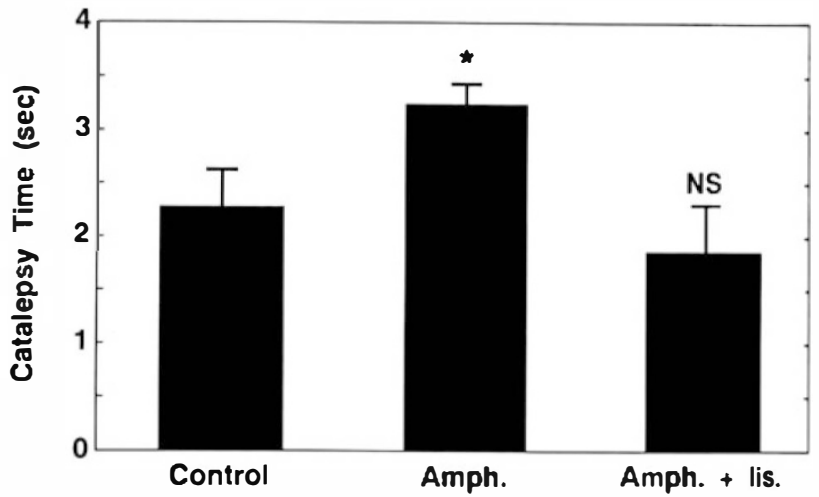

Figure 6. Effect of lisuride on catalepsy time during withdrawal from chronic amphetamine self-administration. For details, see Figure 3 . Number of subjects $=8$ per group. " $p<0.05$.

by the administration of tricyclic antidepressants ( $\mathrm{Ga}$ win and Kleber 1984). When comparing nonhuman models of "depression" to the course of the affective disorder in humans, usually little or no parallelism can be drawn between the natural history preceding human depression and the experimental procedure used to induce the behavioral state of "depression" in animals (Willner 1984). In contrast, the present study provides an animal model of depression that is drug-induced, quantitatively measurable, and has, at the same time, construct and face validity (Willner 1984).

Several studies over the past few years have addressed the issue of postamphetamine depression in animals. Withdrawal from a chronic schedule of experimenter-administered amphetamine has been shown to induce a variety of behavioral changes including reduced rate of responding for electrical self-stimulation reward in rats (Kokkinidis et al. 1986) and elevation of its threshold (Cassens et al. 1981), depression of general activity in rats and cats (Tonge 1974; Feinberg and Irwin 1961), diminished reaction to novel stimuli (Kokkinidis and Anisman 1978), and increased immobility in a forced-swim situation (Kokkinidis et al. 1986). All of these manifestations are considered animal correlates of "depression," and the behavioral syndrome that follows withdrawal from amphetamine administration has been suggested as an experimental model of depression (Leith and Barret 1980). Some of these changes are also reversed by tricyclic antidepressants (Markou et al. in press; Simpson 1974).

It should be noted, however, that some endocrine, immune, and neurochemical changes observed during amphetamine withdrawal in rats do not parallel changes in the same systems observed during endogenous depression in humans (Swerdlow et al. 1991). In the present study, a self-administration rather than experimenter-administered procedure was employed. Under these conditions the animals showed a voluntary in- 
take of high doses of amphetamine. It is noteworthy that a recent report suggests that rats self-administering cocaine assume and tolerate doses that are toxic or lethal for yoked control individuals (Dworkin et al. 1988); in contrast, no deaths were recorded during the present study. The use of intravenous self-administration procedures would therefore have both the advantage of the self-titration of drug intake by each individual animal and a more "natural" temporal pattern of selfinjections (as compared to experimenter-administered procedures) and these may possibly be more closely related to the pattern of drug intake in human addicts.

The major finding of the present report is the effect of lisuride on the behavioral changes described above. lisuride is anergot derivative known to stimulate brain DA receptors of the $D_{2}$ type (Uzumaki et al. 1982; Horowski and Wachtel 1976; Schechter 1984; Cunningham et al. 1987; Rosenfeld and Makman 1981). Lisuride also seems to affect serotonin (5-HT) neurotransmission (Fink and Morgenstern 1985; Cunningham and Lekowski 1990). Indeed, there appears to be a serotonergiccomponent of its locomotor activity effects (Fink and Morgenstern 1985) and lisuride elicits the "serotonin syndrome" characteristic of 5-HT agonists (Sielbergeld and Hruska 1979). Furthermore, a significant proportion of humans maintained on lisuride therapy report hallucinations, which are thought to be mediated by $5-\mathrm{HT}_{2}$ receptors (MacDonald and Horowski 1983). In addition, interference with 5-HT neurotransmission has significant effects on the self-administration of amphetamine and cocaine (Carroll et al. 1990, Loh and Roberts 1990). It is therefore possible that this interaction of lisuride with the 5-HT system is of relevance for the effects of reported treatment with lisuride also reported here.

In a recent report, lisuride reduced cocaine selfadministration (Pulvirenti and Koob submitted). This supports the hypothesis that amphetamine, and other psychostimulant drugs, produce their rewarding action by activating the forebrain DA system (for review, see Pulvirenti and Koob 1990). The rationale for using lisurideduring postamphetamine withdrawal, in contrast, stems from the evidence that a state of DA depletion may occur during the withdrawal phase, as shown by experimental and clinical findings (Wyatt et al. 1988; Gawin and Kleber, 1985; Dackis and Gold, 1985b). Accordingly, bromocriptine, a DA receptor agonist, was shown to decrease cocaine self-administration (Hubner and Koob 1990) and to reverse behavioral signs of cocaine withdrawal in rats (Markou and Koob 1992). Furthermore, clinical studies suggest that bromocriptine showed some beneficial effect during cocaine withdrawal in humans (Dackis and Gold 1985a). Since dysphoria and drug craving are particularly intense during the initial phase of withdrawal from psychostimulant drugs, and these are considered important motivating factors leading to relapse in drug use, the availability of effective and nonaddictive means of pharmacologic intervention is desirable. Lisuride has been extensively used as a prolactin-lowering (Delitala et al. 1979) and antiparkinsonian agent (Schachter et al. 1979). Remarkably, abrupt cessation of the administration of lisuride does not induce withdrawal signs, drug craving, or dysphoria in patients even after administration at high doses through continuous subcutaneous infusion (Bittkau and Pzuntek 1988). Similarly, no reports of nonmedical use of lisuride are known (R. Horowski, personal communication). It is therefore possible to speculate that lisuride may, through stimulation of postsynaptic DA receptors, normalize the DA tone temporarily disrupted by repeated exposure to high doses of amphetamine.

In conclusion, the relative safety of lisuride and the experimental results of the present and previous studies (Pulvirenti and Koob submitted) may encourage clinical trials to assess potential efficacy of the drug in psychostimulant addiction as a mood-stabilizing and "anticraving" agent during withdrawal.

\section{ACKNOWLEDGMENTS}

The authors wish to thank Dr. R. Horowski for the generous gift of lisuride and Dr. Neal R. Swerdlow for helpful discussion. This work was partially supported by NIDA Grants DA 04398. This is publication number NP-6956 of The Scripps Research Institute.

\section{REFERENCES}

Bittkau S, Pzuntek H (1988): Chronic subcutaneous lisuride in Parkinson's disease-Motor performance and avoidance of psychiatric side effects. JNeural Trans 27S:35-54

Carroll ME, Leo ST, Asencio H, Kragh R (1990): Fluoxetine reduces intravenous cocaine self-administration in rats. Pharmacol Biochem Behav 35:237-244

Cassens G, Actor C, Kling M, Schildkraut JJ (1981): Amphetamine withdrawal: Effects on threshold of intracranial reinforcement. Psychopharmacology 33:318-322

Cunningham KA, Lekowski JM(1990): The interaction of cocaine with serotonin dorsal raphe neurons. Neuropsychopharmacology 3:41-50

Cunningham KA, Callahan PM, Appel JB (1987): Discriminative stimulus properties of lisuride revisited: Involvement of dopamine D2 receptors. J Pharmacol Exp Ther 241: 147-151

Dackis CA, Gold MS (1985a): Bromocriptine as treatment for cocaine abuse. Lancet 1:1151

Dackis CA, Gold MS (1985b): New concepts in cocaine addiction: The dopamine depletion hypothesis. Neurosci Biobehav Rev 9:469-477

Delitala G, Wass JAH, Stubbs WA, Jones A, Wiliams S, Besser GM (1979): The effect of lisuride hydrogen maleate, an 
ergot derivative on anterior pituitary hormone secretion in man. Clin Endocrinol 11:1-9

Dworkin SM, Volkmer C, Dworkin SI (1988): Toxic consequences of cocaine are augmented by noncontingent drug administration. Soc Neurosci Abstr 14:961

Feinberg G, Irwin S (1961): Effect of chronic methamphetamine administration in the cat. Fed Proc (Abstr) 20:396.

Fink H, Morgenstern R (1985): Locomotor effect of lisuride: A consequence of dopaminergic and serotonergic actions. Psychopharmacology 85:464-468

Gawin FH, Kleber HD(1984): Cocaine abuse treatment: Open pilot trial with desipramine and lithium carbonate. Arch Gen Psychiatry 41:903-909

Gawin FH, Kleber HD (1985): Neuroendocrine findings in chronic cocaine abusers: A preliminary report. Br J Psychiatry 147:569-573

Gawin FH, Kleber HD (1986): Abstinence symptomatology and psychiatric diagnosis in cocaine abusers. Arch Gen Psychiatry 43:103-107

Horowski R, Wachtel H (1976): Direct dopaminergic action of lisuride hydrogen-maleate, an ergot derivative, in mice. Eur J Pharmacol 36:373-383

Hubner CB, Koob GF (1990): Bromocriptine produces decreases in cocaine self-administration in the rat. Neuropsychopharmacology 3:101-108

Joyce EM, Koob GF (1981): Amphetamine-, scopolamine- and caffeine-induced locomotor activity following 6-hydroxydopamine lesions of the mesolimbic dopamine system. Psychopharmacology 73:311-313

Kokkinidis L, Anisman H(1978): Involvement of norepinephrine in startle arousal after acute and chronic d-amphetamine administration. Psychopharmacology 59:285-292

Kokkinidis L, Zacharko RM, Anisman H (1986): Amphetamine withdrawal: A behavioral evaluation. Life Sci 38:1617-1623

Leith NJ, Barret RJ (1980): Effects of chronic amphetamine or reserpine on self-stimulation responding: Animal model of depression? Psychopharmacology 72:9-15

Loh EA, Roberts DC (1990): Break-points on a progressive ratio schedule reinforced by intravenous cocaine increase following depletion of forebrain serotonin. Psychopharmacology 101:262-267

Markou A, Koob GF (1992): Bromocriptine reverses postcocaine anhedonia in a rat model of cocaine withdrawal. Neuropsychopharmacology 7:213-224

Markou A, Hauger RL, Koob GF: Desmethylimipramine attenuates cocaine withdrawal in rats. Psychopharmacology (In press)

McDonald RJ, Horowski R (1983): Lisuride in the treatment of parkinsonism. Eur Neurol 22:240-255

Pulvirenti L, Koob GF (1990): The neural substrates of drug addiction and dependence. Funct Neurol 5:109-119

Pulvirenti L, Swerdlow NR, Hubner CB, Koob GF (1991): The role of limbic-accumbens-pallidal circuitry in the activat- ing properties of psychostimulant drugs. In Willner $\mathrm{P}_{\text {, }}$ Scheel-Kruger J(eds), The Dopamine System: From Motvation to Action. London, John Wiley and Sons, pp 131-140

Pulvirenti L, Koob GF: Lisuride redures intravenous cocaine self-administration in rats. (Sub.nutted)

Roberts DCS, Vickers G (1984): Atypical neuroleptics increase self-administration of cocaine: An evaluation of a be havioral screen for antipsychotic activity. Psychophar. macology 82:135-139

Roberts DCS, Corcoran ME, Fibiger HC (1977): On the role of ascending catecholaminergic systems in intravenous self-administration of cocaine. Pharmacol Biochem Be hav 6:615-620

Roberts DCS, Koob GF, Klonoff P, Fibiger HC (1980): Extinc. tion and recovery of cocaine self-administration follow. ing 6-hydroxydopamine lesions of the nucleus accum bens. Pharmacol Biochem Behav 12:781-787

Rosenfeld MR, Makman MH (1981): The interaction of liswride, an ergot derivative, with serotonergic and dopa minergic receptors in rabbit brain. J Pharmacol Exp Ther 216:526-531

Schacter M, Blackstock J, Dick JPR, George RJD, Marsden CD, Parkes JD (1979): Lisuride in Parkinson's disease. Lancet 2:1129

Schechter MD (1984): Evidence for a direct dopaminergic effed of lisuride. Pharmacol Biochem Behav 21:185-189

Sielbergeld EK, Hruska RE (1979): Lisuride and LSD dopz minergic and serotoninergic interactions in the "serotonin syndrome." Psychopharmacology 65:233-237

Simpson D (1974): Depressed rates of self-stimulationfollowing chronic amphetamine in the rat: Evaluation of these depressed rates by desmethylimipramine. Presented to the Eastern Psychological Association. Washington D.C., April 19, 1974

Swerdlow NR, Hauger R, Irwin M, Koob GF, Britton KT, Puvirenti L (1991): Endocrine, immune and neurochemical changes in rats during withdrawal from chronic amphets mine intoxication. Neuropsychopharmacology 5:23-31

Tennant FS, Sagherian AA (1987): Double-blind comparison of amantadine and bromocriptine for ambulatory withdrawal from cocaine dependence. Arch Intern Med 147:109-112

Tonge SR (1974): Noradrenaline and 5-hydroxytryptamine metabolism in six areas of the rat brain during postam. phetamine depression. Psychopharmacology 38:181-186

Uzumaki H, Govoni S, Memo M, Carruba MO, Trabucchi M, Spano PF (1982): Effect of GTP and sodium on rat striatal dopaminergic receptors labeled with lisuride. Brain Res 248:185-187

Willner P (1984): The validity of animal models of depression. Psychopharmacology 83:1-16

Wyatt RJ, Karoum F, Suddath R, Fawcett R (1988): Persis tently decreased brain dopamine levels and cocaine. JAMA 259:2996 